Journal of Education and Vocational Research

Vol. 2, No. 2, pp. 38-41, Aug 2011 (ISSN 2221-2590)

\title{
Scientific Output and GDP: Evidence from Countries around the World
}

\author{
Ahmad Jafari Samimi*, Hoda Rezaei Roshan \\ Department of Economics, Firoozkooh Branch, Islamic Azad University, Firoozkooh, Iran \\ *jafarisa@yahoo.com
}

\begin{abstract}
Scientific output is one of the important determinants of economic development in countries around the world. The extremely high scientific productivity of developing countries can be corrected by increased funding as investment on publications and also as a measure of scientific output. The purpose of the present paper is to examine the casual relationship between scientific output and GDP in 176 countries from both developing as well as developed countries. Our findings based on estimated regression models using a panel data for the periods 1996-2007 indicate that except in poor countries, there is a two-way and positive relationship between scientific output and GDP.
\end{abstract}

Keywords: Scientific output, Investment, Publication, Gross domestic product (GDP), Panel data.

\section{Introduction}

The comparison between the GDP and scientific publication statistics provides useful and new information. Science can be a focusing device, helping to define policies for technological development, to identify the main international sources of knowledge, and to link the country with the international scientific and technical trends. The scientific infrastructure is a major support for industrial development, providing the necessary knowledge to enter key industries in the development process (Eduardo, 2001). So when we talk about industry and development, the influence can be on GDP and it is rather obvious that richer countries are able to invest more resources in science and therefore account for the largest number of publications (Holmgren \& Schnitzer, 2004).

In this article, we will be discussed to the investigation of interaction between scientific output and GDP that is firm to this assumption that exist the positive and significant relation between scientific output and GDP. It seems (that) developed countries have higher scientific output in comparison with developing countries. In such a way with knowing the scientific position of the countries can estimate the economic position of them (and vice versa). For example, countries like United State, Britain, Germany, France and Italy have higher scientific output and GDP in comparison with the developing countries. Therefore, we can understand the differences between qualifications and approaches in these two groups of countries easily.

\section{Literature Review}

In developing countries, the growth can be enriching by science and technology policy. In fact, the simplest strategy in developing countries is the increasing strategies of GDP at these countries that should allocate to the research centers and universities (Bilsel \& Oral, 1995). For research in relation between science and technology, the correlation between scientific output and industrial outputs has been counted for 17 countries for the years from 1981 to 1994. The results of this study indicate that with high growth in GDP per capita, the scientific publications are increased (Eduardo, 2001). On contrary, the interaction relationship between scientific output index and GDP index is being analyzed for 31 countries. The results of this research state that the high GDP of the countries doesn't show the high level of the scientific at those countries (King, 2004). Kofi Annan recently called attention to the clear inequalities is science between developing and developed countries and stated this unbalanced distribution of scientific activity generates serious problems not only for the scientific community in the developing countries, but for development itself. The results show that, the richer countries invest more in science and so they have more scientific output; In spite of this fact, many countries like the oil exporter countries that have high GDP per capita, their scientific abilities are slight (Purkayatha, 2004). 
The most important foundations of scientific policy in Europe countries focus on innovation affair and supporting the innovation international system in science. The investment weakness in scientific fundamental researches and development is the major obstacle for researchers to use more researches (Fazeli, 2005). A comparison of Iran with other 15 countries of developed and developing countries until the year 2000 shows that The United States, Britain and Germany stand atop the list with 33.2, 7.8 and 7 percent, respectively, and Iran with $0.12 \%$ stands on thirteenth place among these 16 countries. China, India, and South Korea maintain a considerable difference and a relatively higher position in terms of scientific output as compared with Turkey, Egypt, Saudi Arabia, Iran, Pakistan, Kuwait and Iraq (Moin et al, 2007). Also, the comparison of the creation research output with the neighboring countries and the Croatian universities with the largest Slovenian, Hungarian, and Serbian universities indicates that the Croatian science exhibits research output as expected for the given level of GDP (Podobnik \& Biljakvik, 2008). Considering to the relationship between scientific output and GDP in Western Europe indicate that there is a positive relationship between them (Canario, 2009).

\section{Methodology}

Common statistics at this article is included the information in relation to the 176 countries of the world. So, according to the IMF ranking of studied countries, it is classified to 27 developed countries and 150 developing countries. On this basis, the data of the countries in relation to the number of the published articles by scientists and researchers is illustrated in magazines and ISI (Institute for Scientific Information) and is being used as scientific output index in the years from 1996 to 2007. For recognizing the economic development index, the data of GDP (PPP) for 176 countries is taken from IMF from 1996 to 2007. The selected model at this article is the pooled cross-section and time-series data with the using of the data panel.

In present article, we use Granger Causality Test for the 176 developed and developing countries. After recognizing that there is a two-way relationship between scientific output and GDP (PPP), we estimate the Model. The studied model with pooled method (panel) is as follow:

$$
\begin{aligned}
& \qquad \hat{D} P_{i t}=C(1)+C(2) D \hat{O} C_{i t} \\
& D \hat{O} C_{i t}=C(3)+C(4) G \hat{D} P_{i t} \\
& G \hat{D} P_{i t}={ }_{\text {Gross Domestic Product }} \\
& D \hat{O} C_{i t}(\text { Document })={ }_{\text {Science Output }}
\end{aligned}
$$

The kind of the estimation is being recognized with F-statistic. If accounted $\mathrm{f}$ be bigger than critical $\mathrm{f}$, the null hypothesis will not accepted and the fixed effects method will select. Eviews software was used to carry out the analyses.

\section{Results}

Tables 1, 2 and 3 indicate the whole regression coefficient between scientific output and GDP (PPP) for 176 world countries from 1996 to 2007. The developed countries and developing countries signify in both regressions statistically and null hypothesis that there isn't two-way relationship between scientific output and GDP (PPP) at these countries is failed. Therefore, the two-way and positive relationship between scientific output and GDP (PPP) of these countries is going on in long-run.

Table 1: Granger Causality Test between science output and GDP (PPP) for 176 countries (Lags: 1)

\begin{tabular}{ccc}
\hline Null Hypothesis & F-Statistic & Probability \\
\hline GDP(PPP) doesn't Granger Cause Doc & 43.95 & $4.3 \mathrm{E}-11$ \\
Doc doesn't Granger Cause GDP(PPP) & 63.60 & $2.5 \mathrm{E}-15$ \\
\hline
\end{tabular}


Table 2: Granger Causality Test between science output and GDP (PPP) in developed countries (Lags: 2) Null Hypothesis $\quad$ F-Statistic Probability

\begin{tabular}{lcc} 
GDP(PPP) doesn't Granger Cause Doc & 3.38 & 0.02395 \\
Doc doesn't Granger Cause GDP(PPP) & 6.97 & 0.00109 \\
\hline
\end{tabular}

Table 3: Granger Causality Test between science output and GDP (PPP) in developing countries (Lags: 1)

\begin{tabular}{ccc}
\hline Null Hypothesis & F-Statistic & Probability \\
\hline GDP(PPP) doesn't Granger Cause Doc & 114.765 & $5.7 \mathrm{E}-26$ \\
Doc doesn't Granger Cause GDP(PPP) & 108.642 & $1.0 \mathrm{E}-24$ \\
\hline
\end{tabular}

For estimating, the model is being used from fixed effects method because F-statistic is used and the null hypothesis is failed. The result of model estimation has been indicated in static state and with using of the fixed effects and the simultaneity weight least squares in table 4.

Table 4: The Results of Model estimation with panel data

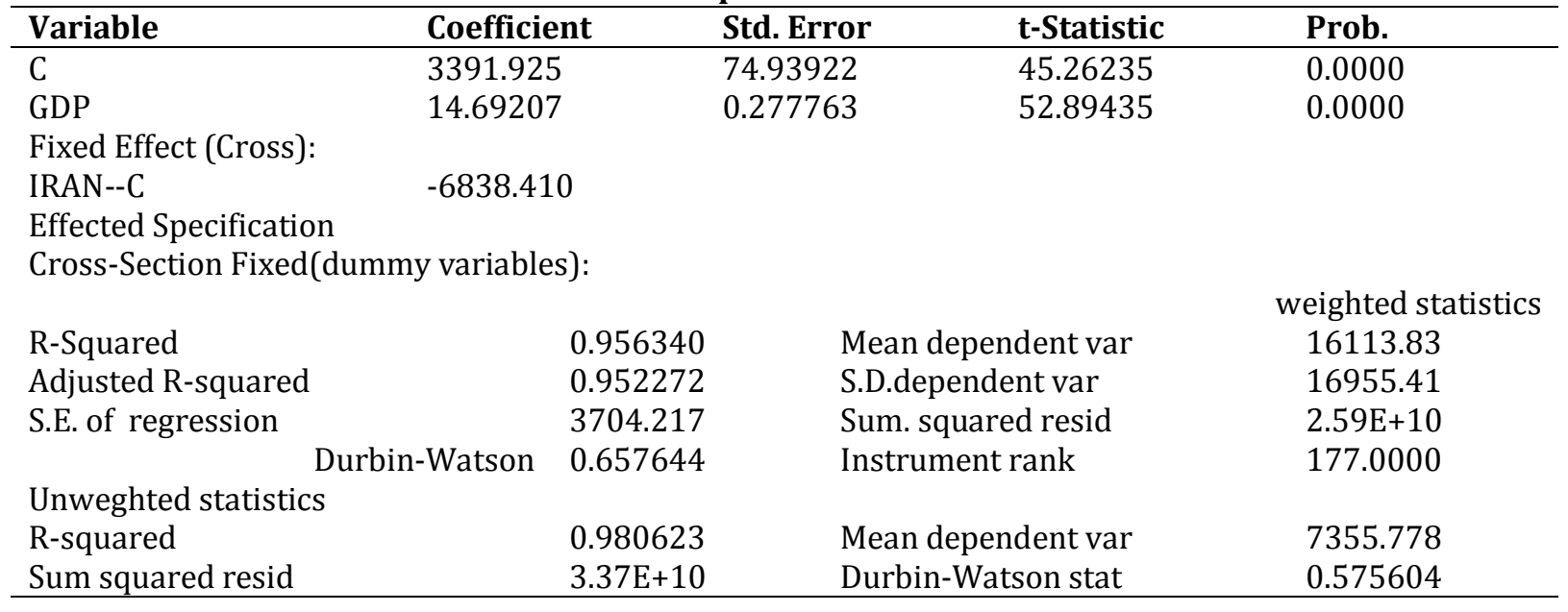

The results of the fixed effects state that the coefficients of the developed countries except 5 countries (Island, Ireland, Portugal, Luxembourg and Malta) has been estimated positive that is according to the theory expectations. On contrary, these coefficients have gotten negative for the most developing countries such as Iran and Middle East oil producing countries. Among the developing countries, only China, India, Turkey and Taiwan have the high economic growth in the recent years and also the coefficients in Russian Federation, Poland, Korea, Hungary and Czech Republic is being estimated positive. According to the table, the amount of $\mathrm{R}^{2}$ is estimated 0.98 that indicate how well the model fits their data.

For examination of the special effects at every country, the assessment of the relation between countries with panel data indicates the countries separately. The simultaneity effect of scientific output and GDP in developing countries has explained well and the coefficients are positive. The results of the model estimation in the simultaneity effect of GDP and scientific output in Iran indicate the adjusted coefficient of determination about 0.93 . The slope of the regression line for Iran is assessed positive that want to say the positive relation between scientific output and GDP of Iran. This coefficient for whole critical regions is estimated significant. The relation between scientific output and GDP in developing countries like Maldives, Niger, Sierra Leone, Tajikistan, Turkmenistan, Uzbekistan, Djibouti, Albania and El Salvador that are very poor in economic and scientific have strong dependence to other countries is estimated so weak and explain a few amount of the original variability at these countries. On contrary, in developing countries like China, Egypt and Malaysia, $\mathrm{R}^{2}$ at this model is more than \% 90. In fact, the relation between scientific output and GDP at these countries has gotten positive and also significant. 


\section{Conclusion}

The result of using panel data shows that there is a two-way and positive relationship between scientific output and GDP. Therefore, in developed countries with higher scientific output or GDP, increasing in each of the two can increase the other one. There's positive relationship in the most developing countries too, but this relationship is not as strong as the case of developed countries. However, in some developing countries that are very poor in both scientific and economic output the two-way relationship is not confirmed, because they do not have high scientific output to be effective on GDP and also do not have high GDP to have scientific output with investment on universities and science section.

As a limitation, there is not support by universities to invest on research that the researchers want to do in developing countries. In addition, the staff's knowledge and abilities are not enough at the universities so it can be an obstacle on the way of researchers and also it make them to miss their motivations. As a remark, the economic position of every country return from technology, so it is important to discover how the scientific output lead to innovations and new technology and what that mean to the rational support of the science and technology. Therefore, the best things that the government can do are at first to discover how scientific output improve the economics of the country and then support the researches in their financial problems and also cherish the people who do the research.

\section{References}

Bilsel, A. \& Oral, O. (1995). Role of Education, Science and Technology in Developing Countries. Gazimagas: North Cyprus.

Canario, V. M. A. (2009). Time for Change in Portuguese Science. University of Algarve, Portugal, May. (http://www.ualg.pt/nacanario/time-for-change-in-portuguese-sc.htm)

Eduardo, da M. A. (2001). Scientific Infrastructure and Catching up Process: Notes about a Relationship Illustrated by Science and Technology Statistics, RBE Rio de Janeiro, 55(4), 545-566.

Fazeli, N. (2005). The Recently Policies of Scientific and Technology Output in Britain. The Magazines of the Humanist Sciences Research and Planning Terms at Higher Education, 35-36.

King, D. A. (2004). The Scientific impact of Nations: What Different Countries Get for Their Research Spending. Nature, 430, 311-316.

Moin, M. Mahmoudi, M. \& Rezaei, N. (2007). Scientific Output of Iran from 1970 to 2002. The Hakim Research Journal, 10(2), 8-14.

Podobnik, B. \& Biljakovic, K. (2008). Scientific Output of Croatian Universities: Comparison with Neighboring Countries. Interdisciplinary Description of Complex Systems, 6(1), 28-36.

Purkayatha, P. (2004). Scientific Capability and the Wealth of Nations, Communist Party of India (Marxist), 28 (50).

Schnitzer, S. A. \& Holmgren, M. (2004). Science on the Rise in Developing Countries. SCImago Journal \& Country Rank. 2(1), 10-13. 